\title{
PREVENÇÃO À VIOLÊNCIA NO NAMORO E PROMOÇÃO DE HABILIDADES DE VIDA EM ADOLESCENTES'
}

\author{
Sheila Giardini Murta² \\ Bruna Roberta Pereira dos Santos ${ }^{2}$ \\ Larissa Almeida Nobre ${ }^{3}$ \\ Ivy Fonseca de Araújo ${ }^{2}$ \\ Ana Aparecida Vilela Miranda ${ }^{2}$ \\ Ísis de Oliveira Rodrigues ${ }^{2}$ \\ Claudio Teodoro Peixoto Franco ${ }^{2}$
}

Resumo: Este estudo avaliou efeitos de uma intervenção preventiva sobre a intenção de enfrentamento à violência no namoro e crenças sexistas e homofóbicas entre adolescentes. Participaram 60 adolescentes alocados não randomicamente em duas condições experimentais: $\mathrm{Cl}(\mathrm{N}=27)$ e $\mathrm{CC}(\mathrm{N}=33)$. Enquanto a $\mathrm{CC}$ não recebeu nenhuma intervenção, a $\mathrm{Cl}$ recebeu uma intervenção acerca de gênero, direitos e habilidades de vida, em sete sessões grupais. Os resultados, analisados por meio de sentenças incompletas aplicadas antes e após o programa, apontaram maior redução em crenças sexistas e homofóbicas entre os participantes da $\mathrm{Cl}$ em comparação aos da CC. Os resultados em intenção de enfrentamento à violência no namoro foram similares entre as condições experimentais, com aumento em intenção de negociação e redução em intenção de resignação e violência. Foi relatada a prática de habilidades interpessoais durante e após o programa, aos cinco meses de follow-up. São discutidas as contribuições e limitações deste estudo.

Palavras-chave: Prevenção. Adolescência. Estudo de avaliação. Violência de gênero. Habilidades de vida.

1 Os autores agradecem pelo apoio à pesquisa concedido pelo CNPq (Edital Saúde da Mulher, Processo 551319/2007-0), FINATEC (Edital Enxoval para Novos Docentes-2009) e ao Decanato de Pesquisa e Pós-Graduação da Universidade de Brasília (Edital de Apoio para Novos Docentes-2009).

2 Universidade de Brasília, Brasília-DF, Brasil.

3 Universidade de Granada, Granada, Espanha. 
Relações íntimas caracterizadas por maus-tratos têm sido identificadas como um problema relevante na saúde de jovens e adultos de diferentes países (Blázquez, Moreno, \& García-Baamonde, 2009; Schraiber, D'Oliveira, \& França Jr., 2008; World Health Organization [WHO], 2010; Wubs et al., 2009). Em se tratando de violência entre parceiros íntimos restrita ao namoro, um estudo com uma amostra de 455 jovens universitários de São Paulo encontrou uma prevalência de 21,1\% de agressão (Aldrighi, 2004). Dentre os tipos de agressão, as mais frequentes foram a violência psicológica e a coerção sexual. Uma análise das agressões físicas de maior gravidade mostrou que $72,4 \%$ delas foram práticas mútuas, em que ambos os parceiros agridem e são agredidos. A bidirecionalidade da violência ou prática recíproca entre ambos os parceiros adolescentes foi também constatada por Minayo, Assis e Njaine (2011) em um estudo com 3.200 adolescentes oriundos de várias regiões do Brasil.

A violência no namoro é definida como qualquer comportamento para controlar ou dominar o parceiro, por meios físicos, psicológicos ou sexuais, gerando sofrimento e danos para a saúde e o desenvolvimento (Cornelius \& Resseguie, 2007). Pode ocorrer em relações de curta (como o "ficar") ou longa duração (como o noivado). Essa forma de violência se configura como um precursor da violência intrafamiliar (WHO, 2010) e está associada a outros danos à saúde mental, para parceiros de ambos os sexos, como abuso de drogas, depressão e transtorno de estresse pós-traumático (Anacona, 2008; Caridade \& Machado, 2006; Randle \& Grahman, 2011).

A perpetração da violência no namoro e a vitimização compartilham, em parte, os mesmos fatores de risco, como testemunhar violência entre os pais, ser vítima direta de violência pelos pais (Cyr, McDuff, \&Wright, 2006; Gil-Gonzales, Vives-Cases, Ruiz, Carrasco-Portino, \& Álvarez-Dardet, 2007; Hickman, Jaycox, \& Aronoff, 2004), sofrer abuso sexual (DiLillo, Giuffre, Tremblay, \& Peterson, 2001), conviver com amigos que são violentos com seus parceiros íntimos (Arriaga \& Foshee, 2004), ter crenças sexistas, aceitar a violência como meio natural de resolução de conflitos e ter déficits em habilidades sociais assertivas, de manejo da raiva e autocontrole emocional (Anacona, 2008; Caridade, \& Machado, 2006; Hickman et al., 2004). Por outro lado, habilidades sociais e apego seguro com os pais foram identificados como fatores de proteção para a vitimização por violência no namoro (Maas, Fleming, Herrenkohl, \& Catalano, 2010). Conforme proposto pela Teoria da Aprendizagem Social de Bandura (O'Keefe, 1998), é plausível supor que a convivência com cuidadores e amigos violentos ensine modos de se relacionar afetivamente pautados em crenças sexistas e condutas impulsivas, não responsivas e agressivas, gerando déficits em habilidades sociais relevantes no manejo de conflitos e problemas interpessoais.

Por isso, torna-se coerente como estratégia preventiva o desenvolvimento de habilidades de relação interpessoal, comunicação assertiva, manejo das emoções, empatia, tomada de decisão e pensamento crítico 
acerca dos papéis de gênero, denominadas habilidades de vida pela Organização Mundial da Saúde (WHO, 1997). Contudo, uma revisão dos programas preventivos à violência no namoro (Cornelius, \& Resseguie, 2007) revelou que nem sempre tais componentes são oferecidos, e parte dos programas se restringe à psicoeducação sobre o que é e como se manifesta a violência no namoro com a finalidade de facilitar o reconhecimento de relações íntimas abusivas. Uma análise de programas de prevenção à violência entre parceiros íntimos em países distintos como Portugal (Matos, Machado, Caridade, \& Silva, 2006), Espanha (Gómez, 2007), Estados Unidos (Schwartz, Magee, Griffin, \& Dupuis, 2004) e Índia (Verma et al., 2006) mostra que o conteúdo desses programas é diverso, ora incluindo ora omitindo a promoção de pensamento crítico quanto aos papéis de gênero e habilidades de comunicação e manejo de emoções. Por exemplo, o programa de Matos et al. (2006) tratou de informações sobre causas, prevalência e tipos de maus-tratos nas relações amorosas; desmistificação de crenças sobre a violência nas relações íntimas, rede de serviços de apoio e enfrentamento em caso de violência no namoro. Nessa mesma linha, o programa de Gómez (2007) abordou a desmistificação de crenças sobre a violência no namoro e incluiu capacitação para detecção e reconhecimento da mesma. Já os estudos de Verma et al. (2006) e Schwartz et al. (2004) incluíram em seu conteúdo a discussão das normas tradicionais de papéis de gênero e as habilidades de comunicação com o parceiro, respectivamente. $O$ programa de Verma et al. (2006) abordou a negociação sobre o uso de preservativos, riscos e prevenção a doenças sexualmente transmissíveis; violência na comunidade, na família e com o parceiro; gênero e sexualidade;e saúde reprodutiva. Schwartz et al. (2004) incluíram os temas: papéis de gênero e conflitos de papéis de gênero; táticas de resolução de conflitos aprendidas na família de origem; manejo da raiva; comunicação assertiva; e identificação e expressão de emoções. A julgar pelos resultados positivos encontrados por Schwartz et al. (2004), pode-se supor que programas que sejam centrados numa perspectiva de gênero e direitos humanos (WHO, 2010) e incluam o desenvolvimento de habilidades de vida produzam resultados mais abrangentes e duradouros, tal como recomendado em revisão recente da área (Muñoz-Rivas, Graña, \& González, 2011).

Abordar o manejo de emoções e o pensamento crítico acerca dos papéis de gênero ganha sentido tendo em vista que os estereótipos de papéis de gênero masculino e feminino encerram diversos tabus quanto ao reconhecimento e à expressão de emoções para homens e mulheres. Enquanto se espera do homem a dureza, a competição e a insensibilidade (Louro, 2007; McDermott, Schwartz, \& Trevathan-Minnis, 2012), espera-se da mulher a docilidade, a gentileza e a subserviência (Louro, 2007). A masculinidade e a feminilidade assim construídas afetam o modo como são manejados conflitos nas relações amorosas. Padrões de interação entre, de um lado, a submissão à violência e a obrigação de cuidar (para a 
mulher) e, de outro, a dureza e a impulsividade na expressão das emoções (para o homem) tendem a potencializar disfunções relacionais. De fato, diversos estudiosos (Leasel et al., 2010; McDermott, \& Lopez, 2012) têm constatado que a conformidade com tais estereótipos de papéis de gênero masculinos está associada à tolerância à violência nas relações íntimas e à supressão de emoções. Têm-se, como resultado, déficits em habilidades sociais de autoexpressão emocional e o uso da violência como estratégia de resolução de conflitos nas relações de namoro.

Esses não são atributos naturalmente masculinos ou femininos, mas construções culturais que moldam as identidades de gênero. As práticas culturais, empreendidas por família, escola, pares, igreja e mídia, transmitem normas de comportamento aceitáveis e inaceitáveis, tomando como referência a heteronormatividade (Louro, 2007). Segundo esta, o homem heterossexual é a norma a partir da qual se estabelecem comparações, hierarquias e ideologias de superioridade de um gênero sobre o outro (sexismo) e de uma orientação sexual sobre a outra (heterossexismo). Como consequência, mulheres e homossexuais ocupam espaços de poder inferiores e são vítimas de violências, desde as invisíveis, como o desprezo, até as fatais, como assassinatos. Portanto, a violência contra a mulher e contra os homossexuais, isto é, a homofobia, compartilham a mesma origem e "constituem as duas faces da mesma intolerância" (Borrillo, 2009, p. 20). É pertinente, portanto, que os programas de prevenção à violência no namoro promovam, para além do ensino de habilidades de vida, o questionamento de crenças e condutas sexistas e homofóbicas e os direitos sexuais e reprodutivos.

Apesar da violência de gênero ser altamente prevalente na América Latina, a violência no namoro é um tema de pesquisa pouco explorado, excetuando-se alguns estudos feitos no Brasil (Aldrighi, 2004; Nascimento \& Cordeiro, 2011; Minayo et al., 2011), Argentina, Peru e México (Hernandez, Lira, \& Mendoza, 2009; Hernandez \& Mendoza, 2009; Pick, Leenen, Givaudan, \& Prado, 2010). À exceção do estudo de Pick et al. (2010), que abordou a avaliação de um programa preventivo, os demais foram descritivos ou correlacionais e apontaram a violência entre parceiros íntimos jovens como um problema, para o qual contribuem o desenvolvimento de papéis de gênero sexistas e a falta de habilidades de negociação dos modos de se relacionar afetiva e sexualmente. É, portanto, necessário e urgente que o conhecimento derivado desses estudos seja convertido no desenvolvimento de tecnologias de prevenção à violência no namoro, sobretudo no contexto latino-americano, dada a escassez de estudos.

Nessa linha, o presente estudo trata da avaliação de uma intervenção para prevenção à violência no namoro embasada na promoção de habilidades de vida e direitos sexuais e reprodutivos. Este estudo teve por objetivo avaliar efeitos da intervenção sobre a intenção de enfrentamento à violência no namoro e crenças sexistas e homofóbicas entre 
os adolescentes participantes, em comparação a adolescentes que não receberam a intervenção. Adicionalmente, buscou-se avaliar os efeitos do programa sobre a prática de habilidades ensinadas no decorrer do programa e sua manutenção cinco meses após o término do programa entre os adolescentes participantes.

\section{Método}

\section{Delineamento}

O estudo foi feito por meio de um delineamento quase-experimental, com avaliação de pré e pós-teste, avaliação de processo e avaliação de impacto cinco meses após o término da intervenção, com uso de estratégias quantitativas e qualitativas de avaliação.

\section{Participantes}

Participaram 60 alunos do primeiro ano do ensino médio de uma escola pública da cidade de Brasília, alocados em quatro salas de aula. Duas destas, as turmas $\mathrm{X}$ e $\mathrm{Y}$, do turno matutino, foram designadas não randomicamente para a Condição Intervenção $(\mathrm{Cl} ; \mathrm{N}=27)$, e duas, do turno vespertino, para a Condição Controle ( $C \mathrm{C} ; \mathrm{N}=33)$. Quanto ao sexo, $52 \%$ dos participantes da $\mathrm{Cl}$ eram do sexo masculino e $48 \%$, do feminino, com idades entre 15 e 18 anos. Os participantes do CC eram, em sua maioria (66\%), do sexo feminino, com idades entre 14 e 18 anos. Em relação à religião, na $\mathrm{Cl}, 42 \%$ eram católicos, $38 \%$ evangélicos, $8 \%$ sem religião e $12 \%$ relataram outras. $\mathrm{Na}$ CC, $47 \%$ eram católicos, $31 \%$ evangélicos, $19 \%$ sem religião e $3 \%$ outras religiões. O controle das finanças em $54 \%$ das famílias dos participantes era, na Cl, exercido pelo pai e pela mãe; em 19\%, apenas pela mãe; em $19 \%$, apenas pelo pai; e em $8 \%$, por outros. Na CC, as finanças eram controladas em $49 \%$ dos casos pelo pai e pela mãe; em $30 \%$, apenas pela mãe; em $15 \%$, pelo pai; e em $6 \%$, por outros.

Dos 60 participantes, $27 \%$ deles (CI) e $46 \%$ (CC) namoravam ao início da intervenção. Uma pequena parte, todos do sexo masculino, relatou já ter sido pressionada a fazer sexo $(8 \%-\mathrm{Cl} ; 6 \%-\mathrm{CC})$. Quando questionados se tinham amigos homossexuais, $46 \%(\mathrm{Cl})$ e $61 \%$ (CC) deles responderam de maneira afirmativa. Aproximadamente metade dos participantes em cada uma das condições experimentais relatou que não conversava sobre sexualidade com os pais $(42 \%-\mathrm{Cl} ; 49 \%-\mathrm{CC})$. Cerca de um terço dos participantes, em cada uma das condições experimentais, já havia testemunhado "brigas feias" entre os pais (35\% - Cl; $36 \%-\mathrm{CC})$. Mais da metade deles, em cada uma das condições, relatou ser encorajado pelos pais a fazer uso de anticonceptivo $(84 \%-\mathrm{Cl} ; 66 \%-\mathrm{CC})$. Nenhum 
deles relatou ter vivenciado gravidez, pessoal ou da parceira, ao início da intervenção.

\section{Instrumentos}

Questionário sociodemográfico: composto por 22 questões fechadas sobre idade; sexo; religião; experiência prévia em gravidez, coerção sexual e testemunho de violência entre os pais; problemas de saúde; convívio com amigos homossexuais; papéis de gênero na família de origem e práticas sobre anticoncepção.

Questionário de interesses: o questionário continha a instrução"marque com um $x$ os temas que você gostaria de discutir em nossos encontros e indique outros temas de seu interesse". Onze itens foram apresentados (por exemplo: lidar com ciúme no namoro, ter mais segurança para tomar decisões e usar anticonceptivo). Um espaço para respostas livres foi também oferecido nesse instrumento.

Sentenças incompletas para avaliação de crenças sexistas e homofóbicas e intenção de enfrentamento à violência no namoro: Este instrumento foi aplicado no pré e pós-teste. Compreende doze sentenças incompletas que remetem às crenças sobre papéis de gênero (três sentenças; exemplo: Quando falam que a mulher deve obedecer à vontade do marido, eu penso que isso...), homossexualidade (quatro sentenças; exemplo: Penso que o casamento entre homossexuais é...) e violência no namoro (três sentenças; exemplo: Se um dia meu/minha namorado/a tiver muito ciúme de mim e me impedir de sair com meus/minhas amigos/as, eu...). 0 adolescente foi solicitado a completar livremente as sentenças de acordo com seu modo de pensar.

Formulário para avaliação de dose recebida: a partir da terceira sessão, cada adolescente recebia e preenchia por escrito, ao início da sessão, um formulário com a pergunta: "Nesta semana, o que você colocou em prática do Programa de Habilidades de Vida? Praticar é todo pequeno passo: pensar, desejar ou agir. Escreva aqui:...."

Questionário para Avaliação de Impacto: composto por duas questões fechadas que avaliavam mudanças em modo de pensar ou agir percebidas pelos participantes como decorrentes da intervenção e três questões abertas sobre esses mesmos tópicos e sobre o uso das estratégias aprendidas na intervenção em situações do dia a dia.

\section{Procedimentos}

\section{Condição Intervenção}

No primeiro encontro com os adolescentes da Condição Intervenção, foi conduzido um jogo para avaliação dos conhecimentos e cren- 
ças dos adolescentes sobre diversos temas no campo da sexualidade (exemplos: masturbação e início da vida sexual) e dos direitos sexuais e reprodutivos (exemplos: anticoncepção e homossexualidade). Em seguida, realizou-se uma avaliação de interesses, por meio da aplicação de um questionário com temas previamente estabelecidos que cobriam o conteúdo previsto para a intervenção e uma questão aberta para eventuais sugestões de inclusão de novos temas. Uma devolução desses resultados foi feita aos participantes na segunda sessão, e foi acordado com eles que a ordem de discussão dos temas seguiria aquela por eles estabelecida: dos mais escolhidos aos menos escolhidos. Tal procedimento foi adotado com a finalidade de motivar os adolescentes e encorajar sua adesão à intervenção. Essa medida resultou em diferenças entre as turmas na ordem de abordagem dos temas. A Tabela 1 apresenta o conteúdo da intervenção, por sessão, em cada uma das turmas.

Ao todo, a intervenção oferecida aos participantes da Condição Intervenção foi composta por sete sessões, semanais, de 80 minutos, durante o horário escolar. Foram utilizadas vivências, modelação por exposição

Tabela 1

Conteúdo da intervenção, por sessão e por turma

\begin{tabular}{|c|c|c|}
\hline Sessão & Turma X & Turma Y \\
\hline 1 & $\begin{array}{l}\text { Avaliação de interesses. } \\
\text { Pré-teste. }\end{array}$ & $\begin{array}{l}\text { Avaliação de interesses. } \\
\text { Pré-teste. }\end{array}$ \\
\hline 2 & $\begin{array}{l}\text { Pré-teste (continuação). } \\
\text { Tomada de decisão em contextos de } \\
\text { interação afetivo-sexual. }\end{array}$ & $\begin{array}{l}\text { Pré-teste (continuação). } \\
\text { Reconhecimento de relações de } \\
\text { namoro abusivas e saudáveis }\end{array}$ \\
\hline 3 & $\begin{array}{l}\text { Reconhecimento de relações de } \\
\text { namoro abusivas e saudáveis }\end{array}$ & $\begin{array}{l}\text { Comunicação assertiva, } \\
\text { enfrentamento à } \\
\text { a violência no namoro }\end{array}$ \\
\hline 4 & $\begin{array}{l}\text { Comunicação assertiva e } \\
\text { enfrentamento à violência no namoro }\end{array}$ & $\begin{array}{l}\text { Tomada de decisão em contextos } \\
\text { de interação afetivo-sexual. }\end{array}$ \\
\hline 5 & $\begin{array}{l}\text { Anticoncepção, papéis de gênero, } \\
\text { direitos sexuais e reprodutivos. }\end{array}$ & $\begin{array}{l}\text { Anticoncepção, papéis de gênero, } \\
\text { direitos sexuais e reprodutivos. }\end{array}$ \\
\hline 6 & $\begin{array}{l}\text { Manejo de emoções, papéis de gênero } \\
\text { e empoderamento }\end{array}$ & $\begin{array}{l}\text { Manejo de emoções, papéis de } \\
\text { gênero e empoderamento. }\end{array}$ \\
\hline 7 & Pós-teste & Pós-teste \\
\hline
\end{tabular}


de filme, treino de papéis, exposição dialogada, discussão em pequenos grupos, discussão de músicas e tarefas de auto-observação. Essas técnicas foram usadas para se favorecer o desenvolvimento das seguintes habilidades de vida, aplicadas ao contexto dos relacionamentos íntimos (Murta et al., 2011):autoconhecimento, pensamento crítico, comunicação assertiva, empatia, manejo das emoções, tomada de decisão e resolução de problemas.

As sessões foram conduzidas por uma equipe de seis facilitadores, dos quais uma era aluna de doutorado em Psicologia Clínica e da Saúde, com experiência prévia em intervenções em grupo para adolescentes, e os cinco restantes eram graduandos em Psicologia. Cada sessão seguia uma ordem de procedimentos: (a) sondagem das habilidades praticadas no decorrer da semana com aplicação do Formulário para Avaliação de Dose Recebida, (b) técnica principal (exemplo: vivências grupais), (c) discussão da técnica principal em pequenos grupos sob a coordenação de um facilitador, (d) tarefa de casa e (e) avaliação de satisfação para com a sessão do dia.

\section{Condição Controle}

Os participantes da CC não receberam nenhuma intervenção enquanto os da $\mathrm{Cl}$ estavam participando do programa. Seis meses após o término do programa, a CC recebeu uma intervenção breve. Teve a duração de quatro horas e foi feita em sessão única, em grupo. Essa intervenção foi focada em informações sobre direitos sexuais e reprodutivos e sensibilização para a atribuição desses direitos a si mesmo e ao outro e fez uso de jogos grupais. Seus resultados não serão objeto de análise neste artigo.

\section{Avaliação e análise dos dados}

As avaliações de pré e pós-teste foram feitas na primeira (tendo sido finalizada na segunda sessão) e última sessões, respectivamente. A avaliação de processo foi feita a cada sessão, a partir da terceira. A avaliação de impacto foi conduzida cinco meses após o término da intervenção. Ainda que tenhamos escolhido um delineamento quase-experimental, tradicionalmente associado a estudos quantitativos, adotamos medidas e procedimentos de análise de dados qualitativos e quantitativos neste estudo, assumindo que o delineamento, a coleta de dados e a análise de dados são processos independentes, tal como discutido por Bauer, Gaskell e Allum (2002). Os dados obtidos nas "Sentenças incompletas para avaliação de crenças sexistas e homofóbicas e intenção de enfrentamento à violência no namoro", no "Formulário para avaliação de dose recebida" e as questões abertas do "Questionário para avaliação de impacto" foram examinados por meio de análise de conteúdo (Bardin, 1977). 
Foram feitas leituras dos dados, definidas categorias e inseridos os dados nessas categorias. Dois juízes foram consultados em casos de dúvidas nas categorizações. Foram feitas contagem de frequências de relatos em cada categoria e apresentação dos resultados por meio de frequências e/ ou porcentagens de relatos em suas respectivas categorias. Os dados obtidos nas questões fechadas do "Questionário para avaliação de impacto" e no "Questionário sociodemográfico" e no "Questionário de interesses" foram avaliados por meio da contagem de frequências e porcentagens.

\section{Cuidados éticos}

Este estudo foi aprovado pelo Comitê de Ética em Pesquisa da Pontifícia Universidade Católica de Goiás (Protocolo 0005.0.168.000-08). Diversos cuidados éticos foram tomados antes (convite para participação e esclarecimentos para a direção da escola, pais e adolescentes, por meio do Termo de Consentimento Livre e Esclarecido), durante (supervisão constante para maximizar qualidade da intervenção e prevenir riscos) e depois da coleta de dados (devolução de resultados à escola e oferta de intervenção para adolescentes da Condição Controle).

\section{Resultados}

\section{Avaliação de interesses}

Na Turma $X$, os resultados ao Questionário de Interesses foram, em ordem decrescente:"lidar com ciúmes no namoro" (63\%), "ter mais segurança para tomar decisões" (59\%),"usar anticonceptivo" (54\%),"tomar decisões sobre o início da vida sexual (a primeira vez)" (50\%), "ter iniciativa para resolver problemas" (41\%), "ser menos tímida/o e falar o que pensa e sente" (36\%), "compreender suas reações emocionais" (36\%), "negociar com a família desejos conflitantes (ex.: dormir fora)" (32\%);"conversar com a família sobre sexualidade" (18\%) e "lidar com as gozações de amigos/as sobre a virgindade" $(13 \%)$.

Na Turma Y, os temas de maior interesse foram similares aos da Turma $X$, com pequenas diferenças na ordem de escolha:"ter mais segurança para tomar decisões" (92\%), "tomar decisões sobre o início da vida sexual (a primeira vez)" (84\%), "lidar com ciúmes no namoro" (80\%), "ter iniciativa para resolver problemas" (76\%), "ser menos tímida/o e falar o que pensa e sente" (72\%), "usar anticonceptivo" (64\%), "compreender suas reações emocionais" (56\%), conversar com a família sobre sexualidade" (52\%), "lidar com as gozações de amigos/as sobre virgindade" (48\%) e "negociar com a família desejos conflitantes (ex. dormir fora)" (48\%). 
Pré e pós-teste em crenças sexistas, homofóbicas e intenção de enfrentamento à violência no namoro

A Figura 1 apresenta as frequências de respostas dadas pelos participantes às sentenças incompletas que avaliavam crenças sexistas. As respostas dadas às três sentenças foram agrupadas em quatro categorias: "sexismo hostil," "sexismo benévolo" (conforme denominado por Glick, \& Fiske, 1996), "não sexismo" e"outras."A categoria"sexismo hostil" inclui respostas com defesa de papéis de gênero tradicionais (exemplo: Acho que, no casamento, quando se tem filhos, quem deve trocar fralda e cuidar dos filhos é... "a mulher, a mãe"). A categoria "sexismo benévolo" engloba respostas que revelam preconceito aparentemente mais brando, mas ainda marcadas pelo conservadorismo nas relações de gênero (exemplo: Acho que, no casamento, quando se tem filhos, quem deve trocar fralda e cuidar dos filhos é... "o pai quando a mãe não puder"). A categoria "não sexismo" compreendeu relatos que evidenciavam maior equidade nos papéis masculinos e femininos (exemplo: Acho que, no casamento, quando se tem filhos, quem deve trocar fralda e cuidar dos filhos é... "o casal, deveres iguais"). As respostas inseridas na categoria "outras" foram aquelas que não condizentes com nenhuma das categorias anteriores (exemplo: Acho que as mulheres que fazem trabalhos de homem - frentistas, empresárias, bombeiros - são..."exploração").

Conforme explicitado na Figura 1, houve um decréscimo acentuado em respostas sexistas hostis na $\mathrm{Cl}$ e um ligeiro aumento na CC. Comparando-se o pré e o pós-teste em ambas as condições experimentais, houve ligeiro aumento em respostas sexistas benévolas na $\mathrm{Cl}$ e manutenção de respostas desse tipo na CC. Notam-se, ainda, aumento acentuado em respostas não sexistas na $\mathrm{Cl}$ e ligeira diminuição na $\mathrm{CC}$. Em síntese, os resultados foram, em parte, na direção esperada, indicando que os participantes da $\mathrm{Cl}$, quando comparados consigo próprios ao início da intervenção e com seus pares da CC, apresentaram menos relatos sexistas hostis e mais relatos pró-equidade de gênero ao fim da intervenção.

A Figura 2 mostra a frequência de categorias de respostas referentes às sentenças que avaliavam crenças quanto à homossexualidade nas Condições Intervenção e Controle, antes e após a intervenção. As respostas foram agrupadas em quatro categorias:"homofobia explícita," "homofobia implícita", "não homofobia" e "outras". Na categoria "homofobia explícita" foram incluídos relatos com rejeição aberta à homossexualidade, caracterizando-a como antinatural (exemplo: Acho a homossexualidade.... "pecado, devia ser proibido, nojento, distúrbio"). Na categoria "homofobia implícita", foram inseridas as respostas que evidenciavam rejeição sutil (exemplo: Se meu irmão tivesse um amigo homossexual, eu..." problema dele, eu não tenho nada a ver com isso"). Na categoria "não homofobia" foram agrupadas respostas indicativas de respeito à diversidade de 


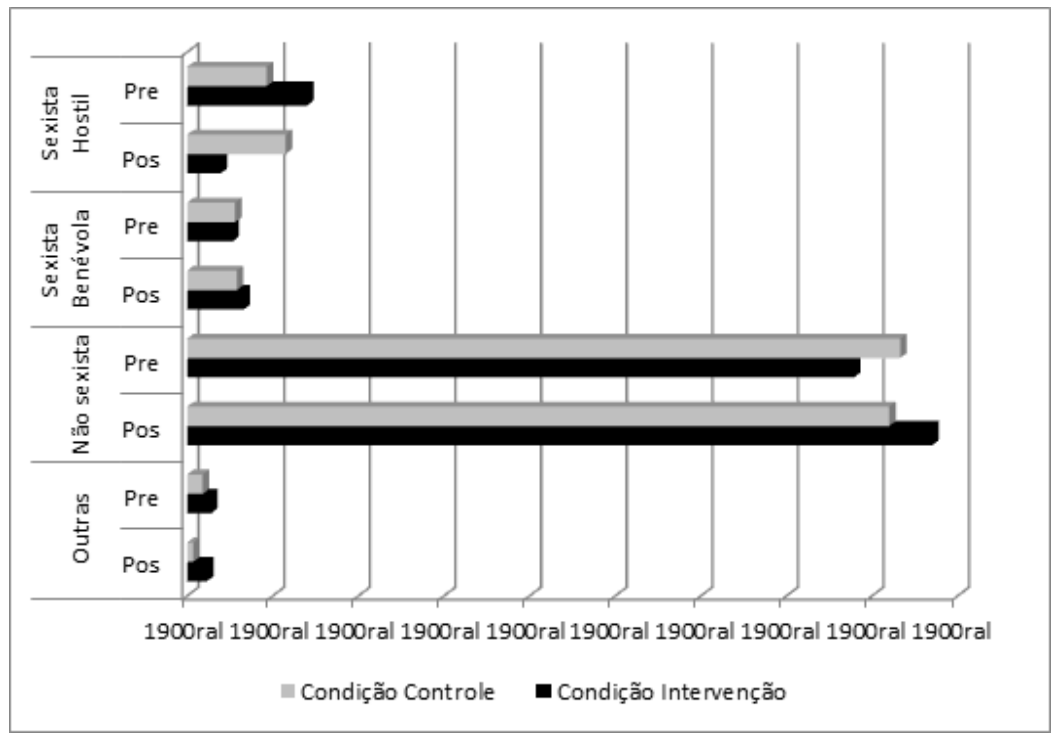

Figura1. Frequência de respostas, por categorias, referentes às crenças sexistas, pré e pós-teste, nas Condições Intervenção e Controle.

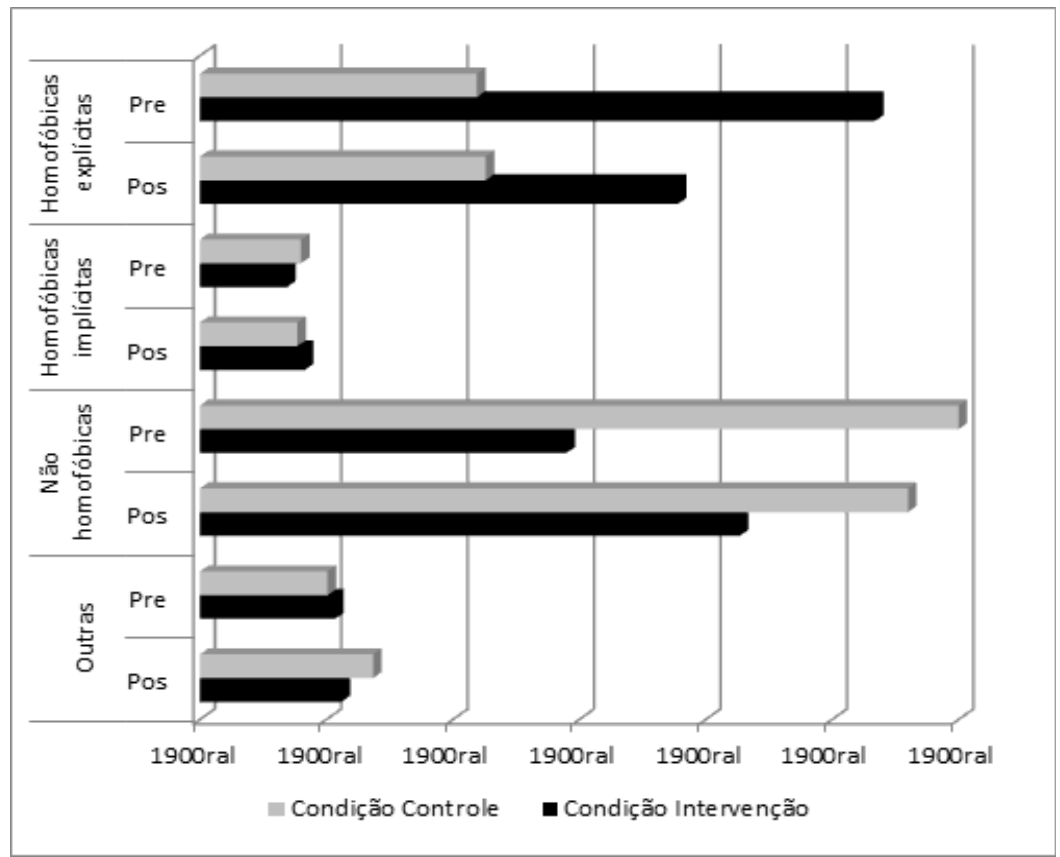

Figura 2. Frequência de respostas, por categorias, referentes às crenças sobre homossexualidade, pré e pós-teste, nas condições Intervenção e Controle. 
orientação sexual (exemplo: Acho a homossexualidade... "opção que deve ser respeitada, normal, direito"). Na categoria "outras" foram classificadas as respostas que não se enquadravam em nenhumas das categorias expostas anteriormente (exemplo: Acho a homossexualidade... "complexa").

Comparando-se o pré e o pós-teste em ambas as condições experimentais, houve diminuição de respostas homofóbicas explícitas na $\mathrm{Cl}$, diferentemente da CC, em que se observou ligeiro aumento nesse tipo de resposta. Constatou-se similaridade na frequência de respostas entre as condições experimentais na categoria de respostas homofóbicas implícitas, com uma tendência a ausência de mudanças entre pré e pós-teste. Houve aumento de respostas não homofóbicas na $\mathrm{Cl}$, diferentemente da CC, em que se observou discreta diminuição nessa categoria. Em síntese, os resultados obtidos nas sentenças que avaliavam crenças sobre a homossexualidade revelaram que os participantes da $\mathrm{Cl}$, quando comparados consigo próprios ao início da intervenção e com seus pares da CC, apresentaram menos relatos homofóbicos explícitos e mais relatos pró-diversidade de orientação sexual, ao fim da intervenção.

A Figura 3 apresenta a frequência de categorias de relatos de intenção de enfrentamento em caso de interação com parceiro/a violento/a. Tais relatos foram classificados em cinco categorias:"enfrentamento com término", "enfrentamento com negociação", "enfrentamento com violência", "enfrentamento com resignação" e "outras". A categoria "término" indica respostas de intenção de interrupção do namoro. A categoria "negociação" corresponde às respostas que indicam a intenção de uso de comunicação para solucionar o conflito. Na categoria "violência", foram incluídas as respostas com ações que indicavam retribuição da agressão física, verbal ou inespecífica. Em "resignação" foram categorizadas as respostas que demonstravam aceitação, concordância ou submissão à situação abusiva. Na categoria "outros", foram reunidas as respostas que não se encaixavam em nenhuma das categorias anteriores.

Os resultados da avaliação por sentenças incompletas, para verificar a intenção de enfrentamento à violência no namoro, foram semelhantes nas duas condições experimentais, comparando-se pré e pós-teste. Ambos os grupos apresentaram, no pós-teste, diminuição na frequência de relatos nas categorias "término", "violência" e "resignação" e aumento na categoria "negociação".Verificamos ausência de mudança na categoria "outros" na CC e diminuição discreta na $\mathrm{Cl}$. Ressaltamos que a frequência de respostas no pré e pós-teste para a categoria "negociação" superou as demais categorias em ambas as condições experimentais. Em síntese, os resultados encontrados no pós-teste foram similares entre as condições experimentais, com aumento de relatos reveladores da intenção de negociação e redução em formas de enfrentamento com violência, resignação e término. 


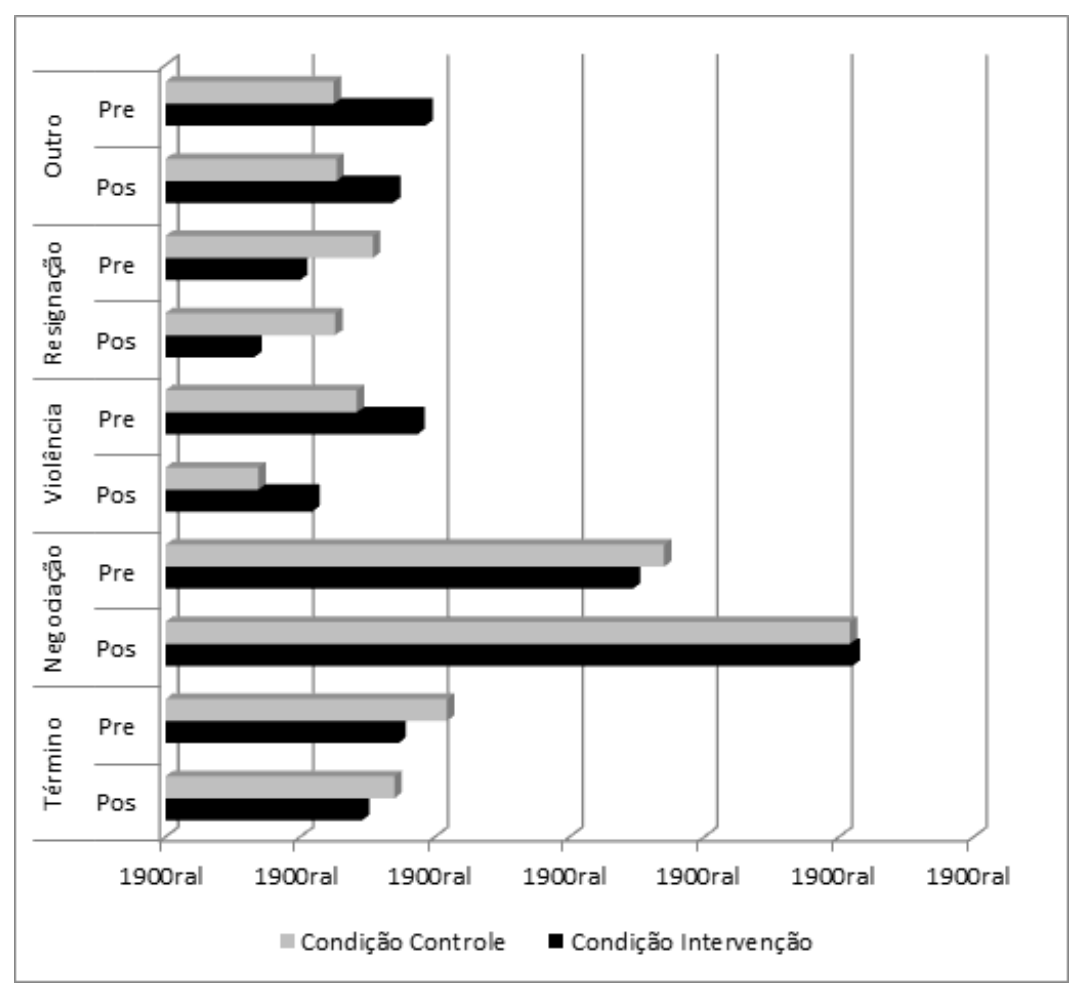

Figura 3. Frequência de respostas por categorias referente à intenção de enfrentamento à violência no namoro, pré e pós-teste, nas condições Intervenção e Controle.

\section{Avaliação de processo}

A análise dos "Formulários de avaliação de dose recebida" evidenciou um total de 107 relatos acerca de uso das ferramentas disponibilizadas na intervenção, coletados ao longo de cinco semanas. Essas ferramentas foram categorizadas em habilidades de vida propostas pela Organização Mundial da Saúde (WHO, 1997), cujas definições estão apresentadas na Tabela 2. A maior parte dos relatos se referiu à prática de habilidades de vida claramente categorizadas (65) e práticas inespecíficas (21). Foram também relatadas a ausência de prática (19) e a disseminação das habilidades aprendidas para amigos e colegas (2). As habilidades de vida mais praticadas no decorrer da intervenção foram Tomada de Decisão (exemplo: "Utilizei o 'quadro de atitudes' para tomar minhas decisões"), Comunicação, com ou sem assertividade manifesta (exemplo:"Conversei com a minha namorada sério, mas sem machucar ela ou a mim mesmo"), Autoconhecimento (exemplo: "Pensei mais sobre minha sexualidade") e 
Empatia (exemplo:“Respeitar e não julgar”). Foram relatados com menor frequência Pensamento Crítico (exemplo: "Acho que mudou um pouco sobre os preconceitos"), Solução de Problemas (exemplo:"Terminei uma relação") e Manejo das Emoções (exemplo:"Estou sendo mais paciente e isto diminui o meu estresse"). A Tabela 2 apresenta as categorias de habilidades de vida, acompanhadas de suas frequências totais e por turma.

\section{Avaliação de impacto}

$\mathrm{Na}$ avaliação de impacto, realizada por meio de questionário com questões fechadas e abertas com 12 adolescentes participantes da $\mathrm{Cl}$ cinco meses após a intervenção, $50 \%$ dos respondentes afirmaram que o programa ocasionou um pouco de mudança na sua forma de pensar, enquanto $25 \%$ afirmaram que o programa trouxe muitas mudanças, e $25 \%$ disseram não perceber mudança alguma. Quanto às mudanças no modo de agir, $33 \%$ relataram não perceber mudanças, $42 \%$ mudaram pouco, e $25 \%$ mudaram bastante.

A análise de conteúdo das respostas dadas pelos adolescentes à pergunta aberta sobre "mudanças em modos de pensar" revelou que, dentre os que afirmaram ter mudado pouco ou bastante em relação ao seu modo de pensar, $25 \%$ dos respondentes obtiveram mudanças na habilidade Pensamento Crítico (exemplo: "Não discrimino mais as pessoas antes de conhecê-las"), 17\% tiveram mudanças na habilidade Empatia (exemplo: "Acho que ouço mais e aceito mais as pessoas"), e $8 \%$ tiveram mudanças na habilidade Tomada de Decisão (exemplo:"Estou pensando muito mais antes de fazer qualquer coisa"). Respostas em branco (25\%), prática não especificada (17\%, ex::"Eu mudei em minhas atitudes em relacionamentos casuais") e sensação de ciúmes ( $8 \%$, "Com relação aos relacionamentos, acredito que passei a ter um pouco mais de ciúmes") foram também constatadas.

A análise de conteúdo das respostas à pergunta aberta sobre "mudanças em modo de agir" evidenciou mudanças na habilidade Manejo das Emoções (17\%, exemplo: "Eu não reajo mais da maneira que eu reagia. Não fico mais emburrada, triste, com raiva, não grito mais"), Solução de Problemas (8\%, exemplo:“Evito confusões”) e Pensamento Crítico (8\%, exemplo: "Acredito que hoje sou uma pessoa mais 'madura' e estou enxergando mais a realidade"). Respostas em branco (34\%), prática não especificada ( $25 \%$, exemplo:"Mudaram as minhas atitudes, não todas, mas a maioria") e expressão de ciúmes (8\%, exemplo:"Comecei a demonstrar mais meus ciúmes") foram também identificados.

Quando indagados se lembravam alguma situação em que haviam colocado em prática o que aprenderam no programa, $58 \%$ deles não responderam à questão e $42 \%$ apontaram algum tipo de prática. Dentre os $42 \%$ dos adolescentes que responderam lembrar-se de alguma situa- 
Tabela 2

Frequência de relatos por categoria de habilidade de vida segundo dados do Formulário de Avaliação de Dose Recebida

\begin{tabular}{|c|c|c|c|c|}
\hline Categoria & Definição & Turma X & Turma Y & Total \\
\hline Tomada de Decisão & $\begin{array}{l}\text { Relatos que incluem reflexão } \\
\text { anterior a uma tomada de } \\
\text { decisão e análise das vantagens } \\
\text { e desvantagens das diferentes } \\
\text { opções de comportamentos } \\
\text { relativos a ela. }\end{array}$ & 6 & 16 & 22 \\
\hline Autoconhecimento & $\begin{array}{l}\text { Relatos sobre o reconhecimento } \\
\text { das próprias qualidades, } \\
\text { dificuldades e recursos, além } \\
\text { da percepção de aspectos em si } \\
\text { mesmo a partir da intervenção. }\end{array}$ & 1 & 8 & 9 \\
\hline $\begin{array}{l}\text { Comunicação não } \\
\text { Especificada }\end{array}$ & $\begin{array}{l}\text { Relatos de diálogo e expressão de } \\
\text { opiniões, desejos, necessidades e } \\
\text { sentimentos, sem especificar, no } \\
\text { entanto, se isso ocorreu de forma } \\
\text { assertiva ou não. }\end{array}$ & 3 & 4 & 7 \\
\hline $\begin{array}{l}\text { Comunicação } \\
\text { Assertiva }\end{array}$ & $\begin{array}{l}\text { Relatos de diálogo e expressão } \\
\text { de opiniões, desejos, medos, } \\
\text { necessidades e sentimentos, } \\
\text { que ocorreram de forma direta e } \\
\text { socialmente apropriada, buscando } \\
\text { conciliar o direito de ambas as } \\
\text { partes. }\end{array}$ & 4 & 1 & 5 \\
\hline Empatia & $\begin{array}{l}\text { Relatos que demonstram interesse } \\
\text { e compreensão das experiências } \\
\text { do outro, assumindo a perspectiva } \\
\text { do interlocutor e inferindo seus } \\
\text { sentimentos ou pensamentos. }\end{array}$ & 5 & 2 & 7 \\
\hline Pensamento Crítico & $\begin{array}{l}\text { Relatos que exprimem reflexão } \\
\text { sobre armadilhas a respeito de } \\
\text { diferenças de gênero, preconceitos, } \\
\text { entre outros, impostas pela mídia, } \\
\text { religião, pares e cultura. }\end{array}$ & 4 & 2 & 6 \\
\hline $\begin{array}{l}\text { Solução de } \\
\text { Problemas }\end{array}$ & $\begin{array}{l}\text { Relatos de ações já implementadas } \\
\text { com o objetivo de amenizar ou } \\
\text { resolver uma situação que causa } \\
\text { incômodo ou desconforto. }\end{array}$ & 5 & 0 & 5 \\
\hline $\begin{array}{l}\text { Manejo das } \\
\text { Emoções }\end{array}$ & $\begin{array}{l}\text { Relatos que envolvem } \\
\text { reconhecimento e autocontrole } \\
\text { da raiva e outros sentimentos } \\
\text { negativos, na tentativa de um } \\
\text { enfrentamento sem causar danos à } \\
\text { própria saúde. }\end{array}$ & 2 & 2 & 4 \\
\hline
\end{tabular}


ção em que colocaram em prática o que aprenderam no programa, 17\% praticaram Tomada de Decisão (exemplo: "Em relação ao meu namoro, pensei no que seria bom para mim, e o que eu poderia fazer, seria melhor uma ou outra atitude"), outros $17 \%$ exercitaram a Comunicação Assertiva (exemplo: "Houve um pequeno conflito, sobre o qual acabamos conversando e nos dando um pouco melhor, em vez de confrontar fisicamente o outro") e um adolescente (8\%) praticou Manejo das Emoções ("Eu parei de agir por impulso").

\section{Discussão}

Os resultados apontam evidências de que os participantes da $\mathrm{Cl}$, em comparação aos da CC, experimentaram mudanças positivas e esperadas, com maior redução em respostas sexistas hostis e homofóbicas explícitas e maior aumento em respostas não sexistas e não homofóbicas. Esses dados sugerem que a intervenção promoveu crenças mais empáticas e menos violentas em relação aos papéis de gênero feminino e à orientação sexual homossexual.

Contrariando a hipótese de superioridade da $\mathrm{Cl}$ sobre a $\mathrm{CC}$, não houve diferenças entre os participantes das duas condições acerca da intenção de enfrentamento à violência no namoro. Nas duas condições, houve no pós-teste redução em intenções de enfrentamento com violência e resignação e aumento em intenções de enfrentamento com término e negociação. Ainda que tais resultados não tenham sido favoráveis à $\mathrm{Cl}$, foram na direção desejada, com aumento em formas saudáveis de enfrentamento (negociação e término) e redução em formas potencialmente nocivas (resignação e violência) nas duas condições experimentais. Deve-se notar que os participantes, já ao início da intervenção, apresentavam respostas majoritariamente não sexistas e não homofóbicas. Estudos futuros poderiam comparar essas variáveis em adolescentes das diversas regiões do país. Além de elucidar eventuais diferenças culturais, tais dados poderiam subsidiar ações preventivas.

De modo geral, os dados do presente estudo encontram-se alinhados aos de estudos prévios de prevenção à violência no namoro, com conteúdo similar ao abordado neste (Cornelius \& Resseguie, 2007; Jaffe, Sudermann, Reitzel, \& Killip, 1992; Muñoz-Rivas et al., 2011; Schwartz et al., 2004), voltados para a construção de habilidades para manejo de conflitos em relações íntimas e embasados em uma perspectiva de gênero, que também produziram resultados positivos. Tais resultados foram corroborados pelos achados das avaliações de processo e de impacto, que mostraram generalização para o cotidiano, durante e após o programa, decorridos cinco meses do seu término. 
É intrigante, contudo, que os resultados em intenção de enfrentamento à violência no namoro tenham sido positivos, mas similares entre as condições experimentais. Uma possível explicação para esse achado é o efeito da medida. Deve-se notar que as sentenças incompletas usadas para se avaliar crenças sexistas (exemplo: Quando falam que a mulher deve obedecer a vontade do marido, eu penso que isso...) e homofóbicas (exemplo: Penso que o casamento entre homossexuais é...) foram distintas das usadas para se avaliar intenção de enfrentamento à violência no namoro (exemplo: Se um dia meu/minha namorado/a tiver muito ciúme de mim e me impedir de sair com meus/minhas amigos/ as, eu....). Nestas últimas, os participantes das duas condições experimentais foram confrontados com uma situação para a qual deveriam fazer um plano de ação, ao passo que, nas anteriores, deveriam apenas dizer o que pensavam sobre o tema. Assim, pode-se supor que as sentenças incompletas acerca da intenção de enfrentamento à violência no namoro funcionaram como uma forma de intervenção, tendo instigado planos de ação (Gollowitzer, 1999) para a solução de problemas interpessoais, como a análise da situação-problema, a previsão de consequências, a identificação de recursos e da solução mais apropriada. Esse é um tópico que requer novos estudos, com contribuição potencial para o desenho de intervenções focadas na construção de planos de enfrentamento e desenvolvimento de instrumentos, qualitativos e quantitativos, de avaliação.

A avaliação de processo, com sondagem acerca da utilização fora da sessão das habilidades de vida ensinadas, revelou que houve transferência para o cotidiano das habilidades abordadas no programa. Os achados dessa avaliação indicam que houve prática de todas as habilidades de vida que foram alvo da intervenção, incluindo as habilidades cognitivas (como Tomada de Decisão) e comportamentais (como Comunicação). Tomada de Decisão foi um dos primeiros temas abordados e foi também o mais praticado pelos participantes. Essa habilidade foi mais praticada na Turma Y, na qual o tema foi trabalhado antes dos demais, por escolha dos adolescentes. Esse resultado parece indicar coerência entre as habilidades praticadas e as oferecidas na intervenção, o que é um indicador favorável à validade interna da intervenção (Kazdin, 2010). A prática das habilidades ensinadas no dia a dia aponta também para a adequação dos procedimentos da intervenção. Tal como discutido por Rapp-Paglicci e Savon (2009), um grande desafio em intervenções preventivas para adolescentes é motivá-los para o programa. Nesse sentido, destacamos medidas adotadas no presente estudo, incluindo o uso da avaliação de interesses dos adolescentes na primeira sessão, a devolução desses dados na segunda sessão e a oferta da intervenção coerentemente com as prioridades elencadas pelos participantes. Isso nos pareceu 
ter promovido interações responsivas entre facilitadores e adolescentes, com consequente favorecimento à adesão dos participantes.

A avaliação de impacto demonstrou que, para parte dos participantes, as habilidades de vida praticadas ao longo da intervenção permaneceram cinco meses após o término do programa. Salienta-se que, para os adolescentes que relataram que a intervenção promoveu mudanças em modos de pensar e agir, as habilidades cognitivas foram mais praticadas do que as habilidades comportamentais. Esse dado se mostrou coerente com as habilidades mais praticadas no decorrer da intervenção (Tomada de Decisão foi a mais praticada). Apenas uma menor parte dos participantes relatou que o programa não gerou nenhuma mudança em seus modos de pensar (25\%) e de agir (33\%). Portanto, a maioria dos participantes relatou no follow-up ter se beneficiado da intervenção e experimentado mudanças em suas formas de pensar e/ou agir. Transferidas para o contexto das relações de gênero, pode fazer uma diferença positiva se relacionar pensando criticamente, reagindo com empatia ao diferente, manejando emoções como a raiva, comunicando-se assertivamente, tendo iniciativa para resolver problemas interpessoais e tomando decisões com ponderação. Estes são recursos que podem empoderar o adolescente (Caridade \& Machado, 2006) e evitar ou reduzir os danos de seu envolvimento em relacionamentos íntimos abusivos (Minayo et al., 2011; Nascimento \& Cordeiro, 2011) e práticas homofóbicas (Borges \& Meyer, 2008).

Dentre os resultados encontrados na avaliação de impacto, chama a atenção uma resposta de um adolescente, que relatou ter começado a demonstrar mais ciúmes. Esse adolescente foi contatado, posteriormente, para melhor compreensão de seu relato escrito no questionário. A julgar pelas suas respostas, é possível que a intervenção tenha promovido maior autoconsciência das emoções e maior expressividade emocional. Não se pode, por outro lado, descartar a possibilidade de efeitos colaterais indesejáveis resultantes de intervenções psicológicas (Barlow, 2010; Castonguay, Boswel, Constantino, Goldfried, \& Hill, 2010). Por isto, são recomendadas avaliações longitudinais e abrangentes dos efeitos de programas de prevenção à violência no namoro.

\section{Considerações Finais}

Em conclusão, os dados sugerem, em parte, evidências de eficácia do programa favoráveis à $\mathrm{Cl}$. Os resultados apontaram maior redução em crenças sexistas e homofóbicas entre os participantes da $\mathrm{Cl}$ em comparação aos da CC. Por outro lado, os resultados em intenção de enfrentamento à violência no namoro foram similares entre as condições 
experimentais, com aumento em intenção de negociação e redução em intenção de resignação e violência para ambas as condições. Resultados positivos foram obtidos na avaliação de processo, que indicou a prática de habilidades interpessoais durante e após o programa, aos cinco meses de follow-up.

Este estudo apresentou algumas limitações. A primeira diz respeito aos instrumentos de avaliação usados, que não contaram com estudos prévios de aferição de sua validade e fidedignidade. Salienta-se ainda que as sentenças incompletas para avaliação de intenção de enfrentamento à violência no namoro parecem ter produzido efeitos pela mera resposta a elas. É clara, portanto, a necessidade de desenvolvimento de novos instrumentos para a população brasileira, quantitativos e qualitativos, para avaliação das variáveis de interesse para programas de prevenção à violência no namoro. Uma segunda limitação é a redução da amostra na avaliação de impacto, o que limita a validade externa do estudo, uma vez que não se sabe que resultados o estudo teve para os que não responderam a essa avaliação, e não se pode, portanto, generalizar esses achados para todos os participantes. Uma terceira limitação é a realização de follow-up apenas com os participantes da Cl. Não se sabe em que extensão esses resultados foram específicos dessa condição experimental. Por fim, a falta de designação randômica entre os grupos ao início da intervenção limita a comparação entre os grupos. Por isto, os achados deste estudo não são conclusivos e deveriam ser comparados a outros que venham corrigir tais limitações.

Ainda que devam ser vistos com cautela, estes dados, resultantes de um delineamento quase experimental, com medidas anteriores e posteriores à intervenção e avaliação de processo e impacto, apontam evidências de que a intervenção foi benéfica na redução de crenças sexistas e homofóbicas e aumento em habilidades de vida, com impacto nas interações cotidianas. Isso justifica a replicação do programa em novos contextos, dados seus achados promissores, bem como a escassez de estudos nacionais em prevenção primária à violência no namoro. Recomenda-se que sejam feitas novas avaliações de eficácia e efetividade do programa, em amostras maiores, com avaliações longitudinais e uso de instrumentos válidos e fidedignos e sensíveis à cultura adolescente. Por fim, variáveis moderadoras e mediadoras dos resultados deverão ser investigadas, tais como sexo, religião, estar namorando e papéis de gênero na família de origem, não exploradas no presente estudo. 


\section{Prevention of dating violence and promotion of life skills with adolescents}

Abstract: This study assessed the effects of a preventive intervention on intention of coping with dating violence and sexist and homophobic beliefs among adolescents. 60 adolescents were allocated not randomly in two experimental conditions: $\mathrm{Cl}(\mathrm{N}$ $=27)$ and $C C(N=33)$. While the $C C$ did not receive any intervention, the $\mathrm{Cl}$ received a seven-group-sessions intervention focused on gender, rights and life skills. The results, analyzed by incomplete sentences applied before and after the program, pointed to a greater reduction in sexist and homophobic beliefs among the $\mathrm{Cl}$ participants in comparison to those from CC. The results on intentions of coping with dating violence were similar between the experimental conditions, with increased negotiation and decreased resignation and violence. The practice of interpersonal skills during and after the program, at five-months follow-up was reported.We discuss the contributions and limitations of this study.

Keywords: Prevention. Adolescence. Evaluation study. Gender violence. Life skills.

\section{Prévention de la violence dans les relations amoureuses et amélioration des habilités pour la vie chez les adolescents}

Résumé: La présente étude évalue les effets d'une intervention préventive sur les intentions d'affrontement violent dans les relations amoureuses et sur les attitudes sexistes et homophobes chez les adolescents. Y ont participé soixante adolescents placés en position non aléatoire en deux situations expérimentales: $\mathrm{Cl}(\mathrm{N}=27)$ et $\mathrm{CC}$ $(\mathrm{N}=33)$. Tandis que le groupe $C C$ n'était l'objet d'aucune intervention, le groupe $\mathrm{Cl}$ au cours de sept sessions de groupe a fait l'objet d'interventions concernant les rôles de genre, ainsi que leurs droits et leurs habilités pour la vie. Les résultats, analysés au moyen de phrases incomplètes appliquées avant et après le programme, ont indiqué une plus grande réduction des attitudes sexistes et homophobes dans le groupe $\mathrm{Cl}$ comparées à celles du groupe CC. Les résultats concernant les intentions d'affrontement violent dans les relations amoureuses ont été semblables entre les conditions expérimentales, avec une augmentation des intentions de négociation et une réduction des intentions de résignation et de violence. On a noté la pratique de habilités pour la vie durant et après le programme, sur une continuité de cinq mois. Sont enfin discutées les contributions et les limitations de cette étude.

Mots-cles: prévention; adolescence; étude d'évaluation; violence de genre; habilités pour la vie. 


\section{Prevención de la violencia en el noviazgo y promoción de habilidades para la vida con adolescentes}

Resumen: Este estudio evaluó los efectos de una intervención preventiva sobre la intención de afrontamiento de la violencia en el noviazgo y las creencias sexistas y homofóbicas entre adolescentes. 60 adolescentes fueron asignados de manera no aleatoria a dos condiciones experimentales: $\mathrm{Cl}(\mathrm{N}=27)$ y $\mathrm{CC}(\mathrm{N}=33)$. Mientras que la CC no recibió ninguna intervención, la $\mathrm{Cl}$ pasó por un programa de siete sesiones grupales que trabajó tres ejes principales: el género, los derechos y las habilidades para la vida. Los resultados fueron evaluados utilizando respuestas a frases incompletas, contestadas antes y después de la intervención. Se verificó una mayor reducción de las creencias sexistas y homofóbicas entre los participantes de $\mathrm{Cl}$ en comparación con los participantes de CC. Respecto a la intención de afrontamiento a la violencia en el noviazgo, los resultados fueron semejantes entre las dos condiciones experimentales, con un aumento en la intención de negociación y reducción en la intensión de resignación y de uso de la violencia. Una evaluación de seguimiento a los cinco meses indicó que las habilidades interpersonales trabajadas fueron utilizadas por los participantes durante y después del programa. Se discuten las contribuciones y limitaciones de este estudio.

Palabras clave: Prevención. Adolescencia. Estudio de evaluación. Violencia de género. Habilidades para la vida.

\section{Referências}

Aldrighi, T. (2004). Prevalência e cronicidade da violência física no namoro entre jovens universitários do Estado de São Paulo - Brasil. Psicologia: Teoria e Prática, 6, 105-120.

Anacona, C. A. (2008). Prevalencia, factores de riesgo y problemáticas asociadas con la violência en el noviazgo: una revisión de la literatura. Avances en Psicología Latinoamericana, 26, 227-241.

Arriaga, X. B., \& Foshee, V. A. (2010). Adolescent dating violence: Do adolescents follow their friends' or their parents' footsteps? Journal of Interpersonal Violence, 19, 162-184.

Bardin, L. (1977). Análise de conteúdo. Lisboa: Edições 70.

Barlow, D. (2010). Negative effects from psychological treatments. American Psychologist, 65, 13-20. 
Bauer, M. W., Gaskell, G., \& Allum, N. C. (2002). Qualidade, quantidade e interesses do conhecimento: evitando confusões. In M. W. Bauer \& G. Gaskell (Orgs.), Pesquisa qualitativa com texto, imagem e som: um manual prático (pp. 17-36). Petrópolis, RJ: Vozes.

Blázquez, M., Moreno, J. M., \& García-Baamonde, M. E. (2009). Estudio del maltrato psicológico, en las relaciones de pareja, en jóvenes universitarios. Electronic Journal of Research in Educational Psychology, 7, 691-714.

Borges, Z. N., \& Meyer, D. E. (2008). Limites e possibilidades de uma ação educativa na redução da vulnerabilidade à violência e à homofobia. Avaliação e Políticas Públicas em Educação, 16, 59-76.

Borrillo, D. (2009). A homofobia. In T. Lionço \& D. Diniz (Orgs.), Homofobia e educação: um desafio ao silêncio (pp. 14-46). Brasília, DF: Letras Livres.

Caridade, S., \& Machado, C. (2006). Violência na intimidade juvenil: da vitimação à perpetração. Análise Psicológica, 4, 485-493.

Castonguay, L. G., Boswell, J. F., Constantino, M. J., Goldfried, M. R., \& Hill, C. E. (2010). Training implications of harmful effects of psychological treatments. American Psychologist, 65, 34-49.

Cornelius, T. L., \& Resseguie, N. (2007). Primary and secondary prevention programs for dating violence: A review of the literature. Aggression and Violent Behavior, 12, 364-375.

Cyr, M., McDuff, P., \& Wright, J. (2006). Prevalence and predictors of dating violence among adolescent female victims of child sexual abuse. Journal of Interpersonal Violence, 21, 1000-1017.

DiLillo, D., Giuffre, D., Tremblay, G. C., \& Peterson, L. (2001). A closer look at the nature of intimate partner violence reported by women with a history of child sexual abuse. Journal of Interpersonal Violence, 16, 116-132.

Gil-Gonzales, D., Vives-Cases, C., Ruiz, M. T., Carrasco-Portino, M., \& Álvarez-Dardet, C. (2007). Childhood experiences of violence in perpetrators as a risk factor of intimate partner violence: A systematic review. Journal of Public Health, 30, 14-22.

Glick, P., \& Fiske, S. (1996). The ambivalent sexism inventory: Differentiating hostile and benevolent sexism. Journal of Personality and Social Psychology, 70, 491-512.

Gollwitzer, P. (1999). Implementation intentions: Strong effects of simple plans. American Psychologist, 54, 493-503. 
Gómez, A. H. (2007). La prevención de la violencia de género en adolescentes. Una experiencia en el ámbito educativo. Apuntes de Psicología, 25, 325-340.

Hernandez, G. S., \& Mendoza, M. P. R. (2009). Recognition and use of sexual coercion tactics in men and women in the context $f$ heterosexual relations: A study of university students. Salud Mental, 32, 487-494.

Hernandez, G. S., Lira, L. R., \& Mendoza, M. P. R. (2009). What is sexual coercion? Meaning, tactics and interpretation in young university students in Mexico City. Salud Mental, 31, 45-51.

Hickman, L. J., Jaycox, L. H., \& Aronoff, J. (2004). Dating violence among adolescents: Prevalence, gender distribution, and prevention program effectiveness. Trauma, Violence \& Abuse, 5, 123-142.

Jaffe, P. G., Sudermann, M., Reitzel, D., \& Killip, S. M. (1992). An evaluation of a secondary school primary prevention program on violence in intimate relationships. Violence and Victims, 7(2), 129-146.

Kazdin, A. E. (2010). Research design in clinical psychology. Boston, MA: Allyn e Bacon.

Lease, S. H., Hampton, A. B., Fleming, K. M., Baggett, L. R., Montes, S. H., \& Sawyer, R. J. (2010). Masculinity and interpersonal competencies: Contrasting white and African American men. Psychology of Men \& Masculinity, 11, 195-207.

Louro, G. L. (2007). Pedagogias da sexualidade. In G. L. Louro (Org.), O corpo educado: pedagogias da sexualidade. Belo Horizonte, MG: Autêntica. Disponível em http:// antropologias.descentro.org/files/downloads/2010/08/LOUROGuacira-L._Ocorpo-educado-pedagogias-da-sexualidade.pdf

Maas, C. D., Fleming, C. B., Herrenkhol, T. I., \& Catalano, R. F. (2010). Childhood predictors of teen dating violence victimization. Violence and Victims, 25, 131-149.

Matos, M., Machado, C., Caridade, S., \& Silva, M. J. (2006). Prevenção da violência nas relações de namoro: intervenção com jovens em contexto escolar. Psicologia: Teoria e Prática, 8, 55-75.

McDermott, R. C., \& Lopez, F. G. (2012). College men's intimate partner violence attitudes: Contributions of adult attachment and gender role stress. Journal of Counseling Psychology, 22, 1-10.

McDermott, R. C., Schwartz, J. P., \& Trevathan-Minnis, M. (2012). Predicting men's anger management: Relationships with gender role journey and entitlement. Psychology of Men \& Masculinity, 13, 49-64. 
Minayo, M. M., Assis, S. G., \& Njaine, K. (2011). Amor e violência: um paradoxo das relações de amor e do ficar. Rio de Janeiro, RJ: Fiocruz.

Muñoz-Rivas, M. J., Graña, J. L., \& González, M. P. (2011). Abuso psicológico en parejas jóvenes. Psicología Conductual, 19, 117-131.

Murta, S. G., Santos, B. R. P., Nobre, L. A., Oliveira, S. A., Diniz, G. R. S., Rodrigues, Í. O. ... \& Del Prette, Z. A. (2011). Diferenciando baladas de ciladas: um guia para o empoderamento de adolescentes em relacionamentos íntimos. Brasília, DF: Letras Livres.

Nascimento, F. S. N, \& Cordeiro, R. L. M. (2011). Violência no namoro para jovens moradores de Recife. Psicologia e Sociedade, 23, 516-525.

O'Keefe, M. (1998). Factors mediating the link between witnessing interparental violence and dating violence. Journal of Family Violence, 13, 39-57.

Pick, S., Leenen, I., Givaudan, M., \& Prado, A. (2010). Yo quiero, yo puedo... prevenir la violencia: Programa breve de sensibilización sobre violencia en el noviazgo. Salud Mental, 33,153-160.

Randle, A. A., \& Grahman, C. A. (2011). A review of the evidence on the effects of intimate partner violence on men. Psychology of Men \& Masculinity, 12, 97-111.

Rapp-Paglicci, L., \& Savon, A. (2009). How can treatment motivation enhance youth prevention programs? Best Practices in Mental Health, 5, 44-51.

Schraiber. L. B., D’Oliveira. A. F. P. L., \& França Jr., I. (2008). Violência sexual por parceiro íntimo entre homens e mulheres no Brasil urbano. Revista de Saúde Pública, 42, 127-137.

Schwartz, J. P., Magee, M. M., Griffin, L. D., \& Dupuis, C. W. (2004). Effects of a group preventive intervention on risk and protective factors related to dating violence. Group Dynamics: Theory, Research and Practice, 8, 221-231.

Verma, R. K., Pulerwitz, J., Vaishali, M., Khandekar, S., Barker, G., Fulpagare, P., \& Singh, S. K. (2006). Challenging and changing gender attitudes among young men in Mumbai, India. Reproductive and Health Matters, 14, 135-143.

World Health Organization. (1997). Life skills education for children and adolescents in schools. Geneva: Programme on Mental Health World Health Organization.

World Health Organization. (2010). Preventing intimate partner and sexual violence against women. Geneva: World Health Organization. 
Wubs, A. G., Aaro, L. E., Flisher, A. J., Bastien, S., Onya, H. E., Kaaya, S., \& Matthews, C. (2009). Dating violence among schools students in Tanzania and South Africa: prevalence and socio-demographic variations. Scandinavian Journal of Public Health, 37, 75-86. 
Sheila Giardini Murta, professora adjunta no Departamento de Psicologia Clínica do Instituto de Psicologia da Universidade de Brasília.Endereço eletrônico: giardini@ unb.br

Bruna Roberta Pereira dos Santos, graduada em Psicologia pela Universidade de Brasília.

Larissa Almeida Nobre, Doutorado em Psicologia da Saúde: Avaliação e Tratamentos Psicológicos pela Universidade de Granada (Espanha). Endereço eletrônico: nobre. lan@gmail.com

Ivy Fonseca de Araújo, graduação em Psicologia pela Universidade de Brasília.

Ana Aparecida Vilela Miranda, graduada em Psicologia pela Universidade de Brasília.

Ísis de Oliveira Rodrigues, graduação em Psicologia pela Universidade de Brasília. Claudio Teodoro Peixoto Franco, graduação em Psicologia pela Universidade de Brasília.

Recebido:07/11/2012

Aceito: $17 / 6 / 2013$ 